DOI: 10.20287/ec.n27.v1.a09

\title{
Inteligibilidade e Mediatismo
}

\author{
Rui Estrada \& Eduardo Paz Barroso \\ Universidade Fernando Pessoa e Citcem / Universidade Fernando Pessoa e LabCom.IFP \\ E-mail: restrada@ufp.edu.pt / epb@ufp.edu.pt
}

\begin{abstract}
Resumo
Neste artigo, dividido em duas partes, discute-se a validade, e a possibilidade, do discurso científico num contexto governado pelo mediatismo e imediatismo da comunicação. Na primeira parte é feito um breve excurso a propósito de questões epistemológi-

natureza empírica, procura demonstar-se que a excessiva mediatização da informação impede uma visão criteriosa e fundamentada dos acontecimentos, ou seja, impede, mesmo em contexto académico, uma narrativa minimamente científica.
\end{abstract} cas. Na segunda parte, através de um exercício de

Palavras-chave: discurso científico; discurso mediático; imediatismo; inteligibilidade.

Abstract: in this paper, divided in two parts, we discuss the validity and the possibility of scientific discourse within a context ruled by mediatization and immediacy in communication. In the first part, a brief incursion is undertaken on the issue of epistemological matters. In the second part, by means

of an empirically minded exercise, we attempt to demonstrate that the excessive mediatization of information prevents an accurate and properly grounded view of the events, that is, it hinders, even within an academic context, the scientific character of narratives.

Keywords: scientific discourse; media discourse; immediacy; intelligibility.

\section{I}

$\mathrm{D}^{\text {LATÃo conta no Teeteto (174a) a famosa anedota de Tales de Mileto, um dos setes sábios da }}$ antiguidade grega.

Enquanto caminhava e observava os fenómenos celestes, Tales caiu dentro de um poço. A serva que o acompanhava, rindo-se da situação, tê-lo-á questionado sobre a pertinência da sua investigação especulativa uma vez nem sabia o que estava mesmo diante dos seus pés.

Data de submissão: 2018-05-02. Data de aprovação: 2018-05-02.

A Revista Estudos em Comunicação é financiada por Fundos FEDER através do Programa Operacional Factores de Competitividade - COMPETE e por Fundos Nacionais através da FCT - Fundação para a Ciência e a Tecnologia no âmbito do projeto Comunicação, Filosofia e Humanidades (LabCom.IFP) UID/CCI/00661/2013.
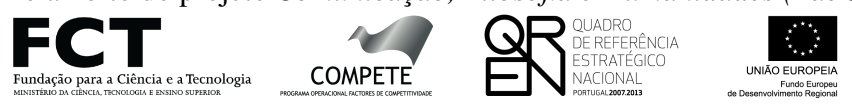

1) 
Esta pequena narrativa pode ser entendida como o início da transição ${ }^{1}$ - protagonizada por Sócrates, no século V a.c. - da filosofia da natureza, a "ciência" entendida à época, para as humanidades. Mais especificamente uma passagem para o campo difuso e antagónico dos assuntos humanos. É este o sentido aqui de 'humanidades': sentido distante, portanto, do restrito entendimento académico e cultural deste domínio na contemporaneidade.

Ora, sabemos, através dos diálogos aporéticos de Sócrates e da querela deste, e de Platão, com os Sofistas, que as humanidades, o saber metaforicamente onde se põem os pés, dão lugar a questões de grande controvérsia. A ordenação das cidades, a ética, os costumes, a justiça, o bem, a arte, entre outros, são, de facto, matérias de debate intenso. A separação entre as ciências da natureza e as ciências humanas estava assumida.

Aristóteles, por exemplo, logo no início da Retórica, separa o conhecimento comum do conhecimento de uma ciência em particular. A retórica e a e dialéctica estão ligadas ao primeiro (1354a).

Um pouco à frente (1357a) reitera esta ideia, afirmando que a retórica delibera sobre questões para as quais não há artes específicas. Não há portanto lugar para a retórica, e para a dialéctica, quando as coisas não podem "ser de maneira diferente", isto é, quando não são de natureza controversial.

Nos Tópicos, a distinção é mais clara: "Há demonstração quando o raciocínio parte de coisas verdadeiras e primordiais, ou de coisas cujo conhecimento tem origem através de coisas primordiais e verdadeiras; ao contrário, é dialéctico o raciocínio construído a partir de coisas plausíveis." (100a).

Em suma, às "certezas" do universo de Tales, e da "ciência" pré-socrática, associam-se as incontáveis polémicas que envolvem os humanos quando descem dos céus.

A separação clássica do conhecimento, grosso modo entre as ciências exactas ou da natureza e as ciências humanas ou sociais, teve uma longa tradição. "As ciências são evidências, as letras são tretas" é ainda hoje a máxima, mais ou menos popular, que explica e legitima a diferença entre estas áreas do saber.

Há igualmente uma literatura muito prolixa, sobretudo a partir da segunda metade do século $\mathrm{XX}$, que teve por desígnio questionar, a vários níveis, esta perspectiva do conhecimento que divide o mundo entre a ciência e as humanidades em sentido geral, entre a objectividade e a mera opinião (Cf., por exemplo, Kuhn, 2003, Rorty, 1988, Goodman \& Elgin, 1988, Davidson, 2005).

O filósofo pragmatista Richard Rorty, num ensaio de 1997 intitulado "Thomas Kuhn, Rocks and the Laws of Physics", critica a hierarquização das áreas de conhecimento a partir de uma maior ou menor aproximação à realidade; a partir de uma maior ou menor cientificidade.

Para Rorty, o que é fundamental é perceber os critérios que determinam e antecipam o sucesso num determinado domínio do saber. Interpretar um texto literário ou conceber um analgésico são actividades diferentes: não se espera da primeira um acordo, nem uma previsão, justamente o que se espera da segunda. Daí não decorre que ler textos literários não tenha já sido, ou não possa vir a ser, uma operação análoga à concepção de uma aspirina. Por outro lado, a produção de

1. Cronologicamente estes pontos não podem ser descritos nesta sequencialidade. Cf. Sobre este assunto Guthrie, 1987, pp. 18 e segs. 
um analgésico terá sido, e sê-lo-á seguramente outra vez, em algum momento da história destes fármacos, tão conturbada como é a interpretação de um texto.

Se partirmos deste exemplo para outros territórios - a política e a física, a matemática e a religião - compreendemos, diz Rorty, que a diferença não reside no binómio retórica/lógica, conhecimento/opinião, mas nos propósitos que uma dada disciplina procura (1999, p. 179).

O que se confunde (daí decorre a crítica que Rorty faz neste ensaio a Steven Weinberg, Nobel da Física) é certos propósitos com a realidade em si mesma, ou seja, a ideia de que em algumas actividades, nomeadamente a da física, apenas se descreve o que acontece no mundo real de forma objectiva e neutra.

Como afirma Rorty: "Se sabemos que tudo o queremos da ciência são predições exactas, temos uma forma automática de decidir entre teorias concorrentes (embora este critério só por si, em certa altura, nos tenha levado a favorecer a astronomia de Ptolomeu em detrimento da de Copérnico). (...) Mas o acordo intersubjectivo é mais difícil de alcançar quando os critérios de sucesso começam a proliferar, e ainda mais quando os próprios critérios são inespecíficos. (...) Esta nova perspectiva sociológica Kuhniana acerca da relação entre as disciplinas tornou as pessoas, em muitas áreas, menos ansiosas relativamente à questão de saberem se os seus métodos de investigação são rigorosos, ou se o seu trabalho produz conhecimento por oposição a mera opinião.” (1999, pp.180-181)

\section{II}

Depois deste breve excurso de natureza epistemológica, procuramos discutir como pode sobreviver o discurso científico ${ }^{2}$, o discurso científico tout court, ao vocabulário fragmentado, imediato e mediatizado que domina hoje o palco principal da comunicação.

Walter R. Fisher diz-nos que a "racionalidade narrativa", na qual também se incluem os textos científicos, deve obedecer dois critérios: a coerência e a fidelidade. O primeiro está relacionado com a contextualização, isto é, qualquer discurso candidato a científico tem de estar envolvido com os discursos anteriores nessa área. O segundo pressupõe uma verificação: os enunciados discursivos são confirmados por evidência empírica, por testemunhos competentes e credíveis. (1994, p. 24)

O problema hoje é que estes dois critérios exigem tempo. Ora, o discurso de hoje é o discurso do momento, do acontecimento. Deste modo, não é possível sequer aferir da validade do enunciado científico, à luz dos princípios de Fisher. Uma contextualização requer que comparemos uma narrativa com as narrativas precedentes, que as conheçamos minimamente para poder levar a cabo essa tarefa. Não serve de muito (não serve de nada os propósitos científicos) concentramo-nos exclusivamente na mera descrição ou na factualidade do que está acontecer.

2. Mesmo para um filósofo pragmatista como Rorty, esta noção de discurso científico continua operacional: "Isto não significa que, para Kuhn, a noção de 'ser científico' seja vazia. Como outras ideias inspiradoras e difusas, pode ser entendida, e concretizada, de várias formas. Uma delas consiste em perguntar se uma dada disciplina nos pode dar previsões exactas, e se, por isso, pode ser útil para a engenharia, para a medicina, ou para outras finalidades práticas". (1999, p. 179) 
Por outro lado a verificação exige um espectro temporal dilatado, não momentâneo; exige ainda uma confirmação competente feita por peritos da área e não seja por quem for indistintamente.

A "racionalidade narrativa" está assim ameaçada nos nossos dias. Isso coloca problemas a nível da aprendizagem, mas também no nosso quotidiano mais simples. Veja-se, por exemplo, o que aconteceu em Lisboa no dia 22 de Setembro de 2014.

Após uma forte tempestade, o vereador da Protecção Civil na Câmara de Lisboa, Carlos Castro (www.publico.pt/local/noticia/chuva-forte-provoca-inundacoes-nas-caldas-da-rainha-1670461\#/ 0), pôs o Instituto Português do Mar e da Atmosfera (IPMA) em causa visto que não tinha sido accionado pelos peritos deste Instituto o alerta laranja para a capital. Não obstante, à boa maneira da agenda política, se ter retractado no dia seguinte, o que o incidente demonstra é que uma narrativa científica, neste caso a narrativa científica do IPMA ${ }^{3}$, foi posta em causa pela pressão do discurso momentâneo e imediato acerca de uma, mais ou menos dramática, ocorrência climatérica.

A avaliação que se faz à altura do acontecimento, ou breves momentos após, mesmo que assumida como científica ou competente, traduz-se, na maioria dos casos, apenas numa impressão. $\mathrm{O}$ rigor científico que pode modificar esta impressão momentânea, justamente porque requer tempo -tempo para aferir a coerência e a fidelidade-, é descartado em nome de uma interpretação imediata.

A narrativa científica não só é negligenciada, como se legitima, neste contexto hipermediatizado, a voz, que já não é apenas vox populi, mas a do comentador, a do entendido no assunto, que é tão mais virtuoso e credível quanto mais depressa emite as suas sábias máximas. Definitivamente o palco mediático nada quer com uma inteligibilidade mínima e fundamentada.

As consequências deste fast thinking (Bourdieu, 1998, pp. 28 e segs.) também se fazem sentir na aprendizagem.

Solicitamos a alunos da área das Ciências da Comunicação ${ }^{4}$ a seguinte tarefa: escrever um editorial tendo em atenção estes dados:

1. O último Relatório Anual de Segurança Interna (RASI, 2014 - http://apav.pt/apav_v2/imag es/pdf/RASI_2014.pdf) que foi tornado público em Abril de 2015; mais concretamente a informação relativa à diminuição da criminalidade violenta e grave (desceu 5, 4\%);

2. Notícias recentes (todas de Abril de 2015), e muito mediatizadas, de criminalidade violenta, a saber: pai mata filho de seis meses (www.publico.pt/sociedade/noticia/bebe-terasido-morto-a-facada-pelo-pai-em-lisboa-1691770), criança de 13 anos violada pelo padrasto (http://www.publico.pt/sociedade/noticia/menina-de-12-anos-gravida-de-padrastronao-pode-abortar-1693832), quádruplo homicídio na Póvoa de Varzim (http://expresso.sap o.pt/sociedade/prisao-preventiva-para-alegado-autor-do-quadruplo-homicidio-na-povoa-d e-varzim=f922391).

3. Cf. a entrevista do Presidente do IPMA, António Pedro Viterbo, que explica a impossibilidade e a irrazoabilidade de fazer uma leitura momentânea de uma narrativa, neste caso previsão, científica (www.publico.pt/multimedia/video/ temporal-em-lisboa-nao-ha-previsao-possivel-2014923140155).

4. O exercício ocorreu na segunda semana de Maio de 2015 e observou todos os preceitos éticos e outros procedimentos próprios para o efeito. 
Verificam-se duas tendências maioritárias nas trinta e quatro respostas: a ideia de que em 2015, face aos crimes recentemente ocorridos, a criminalidade vai subir ou já subiu; a ideia de que, mesmo que a criminalidade não suba, o horror dos crimes é inédito.

Nenhuma destas constatações é fundamentada em qualquer evidência robusta. Pelo contrário, são meras impressões apenas explicáveis à luz sobremediatização/desinformação acerca dos crimes cometidos.

Vejamos o caso da primeira, dando inicialmente nota de algumas respostas:

1. "A grande questão é que estes relatórios mantêm uma atualidade muito pouco rigorosa e confrontando com os casos graves que já ocorreram em 2015 (que ainda nem a meio vai) parece ser evidente essa falta de atualidade."

2. "De acordo com o Relatório Anual de Segurança Interna, a criminalidade grave diminuiu em 2014. No entanto, simultaneamente, as histórias de crimes chocantes que têm vindo a público nos últimos meses parecem contrariá-lo."

3. "No entanto os inúmeros casos noticiados em 2015 fazem crer que este será um ano diferente."

4. "Verificamos que em aproximadamente meio ano o número de casos criminais tem vindo a aumentar."

5. "Se é sabido que a criminalidade violenta diminui em 2014, também é sabido que no ano de 2015 temos assistido a várias situações que contradizem estes factos."

6. "Se continuar a haver mais destes crimes graves, o ano de 2015 terá uma percentagem de criminalidade superior ao ano de 2014."

Como observamos, os respondentes inferem, de forma muito natural, a partir de crimes recentes, conclusões gerais acerca do aumento, putativo ou não, da criminalidade em 2015. Fazemno sem atender a premissas básicas de uma narrativa fundamentada ou científica neste contexto, por exemplo: no período homólogo de 2014, a taxa de criminalidade era maior ou menor? Não obstante a criminalidade violenta ter diminuído em 2014, quantos crimes semelhantes a estes se verificaram nesse período de tempo (certamente mais de três, o que não permite então concluir o que quer que seja de sério para 2015)? Estes três casos são, por mais que um respondente (1, 3, 4, 5 ), englobados no período de tempo de aproximadamente meio ano, esquecendo que se fosse essa a taxa efectiva de criminalidade violenta ao fim de cinco meses, certamente 2015 seria melhor, e não pior, do que 2014.

Atentemos agora na segunda observação infundada: admite-se nas respostas que a criminalidade até possa diminuir em 2015, mas não tínhamos esta barbárie. Transcrevemos algumas respostas, antes da análise e discussão:

1. "Então o que se está a passar em Portugal é que o número de casos de criminalidade violenta diminuiu mas o grau de violência utilizada nos crimes ocorridos foi maior."

2. "A criminalidade voltou a diminuir no ano de 2014 , no entanto, os crimes ocorridos no presente ano têm assumido contornos mais violentos." 
3. "No entanto, em 2015, temos tido uma série de crimes violentos. Como por exemplo, a situação do homicida da Póvoa [quádruplo homicídio na Póvoa de Varzim] podem fazer questionar quão seguro é realmente o nosso país."

4. "Parece que o crime violento tem vindo a diminuir no ano de 2014. Se estamos no bom caminho, por que é que este ano já se registaram crimes absolutamente reprováveis, especialmente pais que cometem atrocidades contra os próprios filhos?"

5. "Estes primeiros meses têm sido muito sangrentos, tanto a nível de homicídios como a nível de violência."

Se é verdade que temos de recuar até 2012 (www.publico.pt/sociedade/noticia/cronologiados-crimes-com-tres-ou-mais-mortos-em-portugal-1693885) para termos notícia de crimes com três ou mais vítimas, em 2104, ano do RASI em estudo, ocorreram homicídios com um grau de violência e de crueldade comparáveis aos dos assassínios recentes. Dois exemplos apenas muito mediatizados à época: em Abril (http://observador.pt/2014/05/21/manuel-palito-baltazar-detidopela-policia-judiciaria/), Manuel Baltazar, conhecido por 'Palito', mata duas pessoas e fere outras duas, uma delas a filha; em Agosto (www.publico.pt/sociedade/noticia/pais-de-bebe-que-morreucom-agua-a-ferver-continuam-a-ser-interrogados-1666800), um bebé de quatro meses morre vítima de queimaduras de água a ferver.

Verificamos então que os respondentes têm uma percepção/impressão instantânea da violência, mas não a relacionam com casos anteriores e documentados. Desta forma, essa violência é sempre única e sobredimensionada, mas apenas na medida em que ocorre no momento. O que temos então é uma perspectiva fragmentada, parcelar, parcial, de que se fala no instante em que ocorre e faz sentido justamente nesse contexto. Muito provavelmente, em 2016, o mesmo exercício conduziria a outra percepção/impressão desta natureza.

O conhecimento transforma-se em informação acumulada, posteriormente esquecida, visto que nunca é relacionada, relacionada de modo crítico e produtivo. Ora, como Fisher diz acima, não pode haver narrativa científica neste contexto em que o acontecimento é soberano.

Há duas respostas que merecem uma atenção particular. Referindo-se a um acidente de viação que ocorreu na madrugada de sábado, 2 de Maio de 2015, no IC2 (http://expresso.sapo.pt/sociedad e/cinco-peregrinos-atropelados-mortalmente-em-cernache=f922736), é afirmado o seguinte:

1. "Desde o início do ano que chegam a todos nós casos de homicídios violentos (...) tal como o de um homem que mata a filha de seis meses, ou então, um jovem que mata 5 peregrinos no IC2."

2. "Por outro lado, acontece também que mal se iniciou 2015 os crimes violentos voltaram a atingir Portugal, o caso do bebé de 6 meses que foi esfaqueado pelo pai (...), o rapaz que no início de Maio assassinou 5 peregrinos (...)."

É necessário ter em atenção que o condutor do automóvel que vitimou os peregrinos, tendo sido ouvido pelo tribunal de instrução, foi indiciado por cinco crimes de homicídio negligente e sujeito a medidas de coacção: inibição de conduzir e obrigatoriedade de se apresentar semanalmente às autoridades (www.dn.pt/inicio/portugal/interior.aspx?content_id=4548518). 
Transformar este quadro jurídico/legal em 'jovem que mata 5 peregrinos no IC2' ou, ainda pior, 'rapaz que no início de Maio assassinou 5 peregrinos' demonstra, uma vez mais, o impacto do momento (o caso ocorre a de 2 de Maio e o trabalho aos alunos é solicitado na semana que se inicia a 11 do mesmo mês) e a dificuldade em relacionar e trabalhar informação básica.

É simplesmente dizer o que quer que seja sem qualquer cuidado ou fundamento. Isto sim representa o fim de qualquer ideia mínima de aprendizagem e a continuação da barbárie discursiva, muito propiciada pelos meios tecnológicos de que dispomos hoje.

Devemos terminar, também por uma questão de elementar justiça, com o exercício que tem o seguinte título: 'Mais crimes em Portugal?' (ver Anexo I). A/o respondente faz aquilo que era suposto fazer: uma interpretação que parte de uma análise comparativa no tempo e não de um sobressalto do momento. Por outro lado, constata, com prudência, que não é possível concluir, a partir dos dados indicados, a tendência da criminalidade para 2015. Vai mesmo mais longe, relevando, na última parte da resposta, o que é factual e está documentado: o crime violento tende a diminuir desde há alguns anos.

Os critérios da coerência e da fidelidade, evocados por Fisher, estão presentes nesta resposta.

\section{ANEXO I}

"Menos crimes em Portugal?

A criminalidade em Portugal tem vindo a diminuir, diz-nos o relatório anual de segurança relativo à criminalidade violenta referente a 2014. De referir que já em 2013 verificou-se o mesmo.

No entanto não deixa de ser preocupante que o relatório se torne público numa altura em que nos deparamos com uma série de crimes violentos, que se tornaram um assunto principal nos meios de comunicação por diversas vezes em 2015.

Contudo isto não significa necessariamente que a criminalidade em 2015 será superior à de 2014, até podemos verificar uma descida. Ainda é cedo para tirar este tipo de conclusões.

Os crimes são uma realidade complicada, mas os estudos já realizados mostram-nos que a tendência é que o número diminua."

\section{REFERÊNCIAS}

Aristotle. (1960). Posterior Analytics. Topica. Cambridge: Massachusetts, Harvard UP.

Aristotle. (2011). Problems, Volume II Books 20-38. Rhetoric to Alexander. Cambridge, Massachusetts, Harvard UP.

Bourdieu, P. (1988). On Television. New York: The New Press.

Davidson, D. (2005). Truth, Language, and History. Oxford: Oxford University Press.

Fisher, W. R. (1994). Narrative Rationality and the Logic of Scientific Discourse. Argumentation, 8: $21-32$.

Goodman, N. \& Elgin, C. Z. (1988). Reconceptions in philoshopy \& Other arts \& Sciences. London: Routledge.

Guthrie, W. K. C. (1987). Os filósofos gregos. De Tales a Aristóteles. Lisboa: Presença. 
Kuhn, T. S. (2003). A estrutura das revoluções científicas. São Paulo: Editora Perspectiva. Plato. (1921). Theaetetus. Sophist. Cambridge: Massachusetts, Harvard UP.

Rorty, R. (1988). A filosofia e o espelho da natureza. Lisboa: Dom Quixote.

Rorty, R. (1999). Philosophy and Social Hope. London: Penguin Books. 